\title{
Determination of tetrabromobisphenol-A/S and their main derivatives in water samples by high performance liquid chromatography coupled with inductively coupled plasma tandem mass spectrometry
}

\author{
Lihong Liu $^{\mathrm{a}, \mathrm{b}}$, Aifeng Liu ${ }^{\mathrm{c}}$, Qinghua Zhang ${ }^{\mathrm{a}, \mathrm{b}, *}$, Jianbo Shi ${ }^{\mathrm{a}, \mathrm{b}}$, Bin He $^{\mathrm{a}, \mathrm{b}}$, Zhaojun Yun $^{\mathrm{d}}$, \\ Guibin Jiang a,b \\ a State Key Laboratory of Environmental Chemistry and Ecotoxicology, Research Center for Eco-Environmental Sciences, Chinese Academy of Sciences, \\ Beijing 100085, China \\ ${ }^{\mathrm{b}}$ College of Resources and Environment, University of Chinese Academy of Sciences, Beijing 100049, China \\ c CAS Key Laboratory of Biobased Materials, Qingdao Institute of Bioenergy and Bioprocess Technology, Chinese Academy of Sciences, Qingdao 266101, China \\ d Agilent Technologies (China) Co., Ltd., Beijing 100102, China
}

\section{A R T I C L E I N F O}

\section{Article history:}

Received 20 December 2016

Received in revised form 16 March 2017

Accepted 17 March 2017

Available online 19 March 2017

\section{Keywords:}

Tetrabromobisphenol-A

Tetrabromobisphenol-S

Derivatives

High performance liquid chromatography Inductively coupled plasma tandem mass spectrometry

Water samples

\begin{abstract}
A B S T R A C T
As the most widely used brominated flame retardants (BFRs), Tetrabromobisphenol-A (TBBPA) as well as its alternative Tetrabromobisphenol-S (TBBPS) and their derivatives have raised wide concerns due to their adverse effects on human health and hence the sensitive detection of those BFRs was urgently needed. Herein, a novel analytical method based on high-performance liquid chromatography (HPLC) coupled with inductively coupled plasma tandem mass spectrometry (ICP-MS/MS) has been developed for the determination of TBBPA/S and their derivatives, including TBBPA-bis(2-hydroxyethyl ether) (TBBPA-BHEE), TBBPA-bis(allylether) (TBBPA-BAE), TBBPA-bis(glycidyl ether) (TBBPA-BGE), TBBPAbis(2,3-dibromopropyl ether) (TBBPA-BDBPE) and TBBPS-bis(2,3-dibromopropyl ether) (TBBPS-BDBPE) in water samples. After optimization, the TBBPA/S and their derivatives, especially the TBBPA-BAE and TBBPA-BDBPE were simultaneously and sensitively quantified by determination of bromine $(\mathrm{m} / z=79)$ by using the ICP-MS. The instrument limits of detection (LODs) for the TBBPA, TBBPA-BHEE, TBBPA-BGE, TBBPA-BAE, TBBPA-BDBPE, TBBPS and TBBPS-BDBPE were determined to be $0.12,0.14,0.19,0.14,0.12$, 0.17 and $0.13 \mu \mathrm{gL}^{-1}$, respectively, which was close to or much better than the reported methods. The relative standard deviations ( $R S D s, n=5$ ) of peak area and retention time were better than $2.2 \%$ and $0.2 \%$ for intra-day analysis, indicating good repeatability and high precision. The proposed method had been successfully applied for the analysis of TBBPA/S and their derivatives in water samples with satisfactory recoveries (67.7\%-113\%).
\end{abstract}

(C) 2017 Elsevier B.V. All rights reserved.

\section{Introduction}

Brominated flame retardants (BFRs) have been widely used in many fields of our lives and concerns have recently been raised due to their persistence, bioaccumulative ability and potential adverse effects to environment and human health [1,2]. Tetrabromobisphenol A (TBBPA) is considered as one of the most important BFRs with the highest production volume, representing about $60 \%$ of the total BRRs market [3]. The European BFR

\footnotetext{
* Corresponding author at: State Key Laboratory of Environmental Chemistry and Ecotoxicology, Research Center for Eco-Environmental Sciences, Chinese Academy of Sciences, Beijing 100085, China.

E-mail address: qhzhang@rcees.ac.cn (Q. Zhang).
}

Industry Panel (EBFRIP) reported that the total global market demand of TBBPA amounted to over $170,000 \mathrm{t}$ in 2004 and the number has continued to increase in recent years since TBBPA was a substitute for polybrominated diphenyl ethers (PBDEs) [4,5]. TBBPA has been widely used as an additive in various flame retardant products such as printed circuit boards, plastics, building materials, textiles and so on to prevent or slowing down the spread of fire $[1,6]$. The TBBPA derivatives, such as TBBPA-bis(2-hydroxyethyl ether) (TBBPA-BHEE), TBBP-A-bis(allylether) (TBBPA-BAE), TBBP-A-bis(glycidyl ether) (TBBPA-BGE) and TBBPA-bis(2,3-dibromopropyl ether) (TBBPA-BDBPE) have also been commonly used as additive or reactive flame retardants in engineer polymers and coatings, epoxy resins, thermoplastic polyesters, polyurethane, polystyrene foams (expandable polystyrene-EPS), polyolefin resins, polystyrene, polyolefins and copolymers [7-9]. 
Meanwhile, the TBBPA analogues such as tetrabromobisphenol-S (TBBPS) and TBBP-S-bis(2,3-dibromopropyl ether) (TBBPS-BDBPE) were widely used as BFRs in Asia [10].

With the continuously growing number of production and ubiquitous application of TBBPA/S and the derivatives, those potentially hazardous chemicals would be released into the environment [11]. Recently, TBBPA and the derivatives, such as TBBPA-BAE, TBBPABDBPE and TBBPS-BDBPE have been detected in various matrices, such as air, dust, water, soil, sediment, biological and food samples $[8,10,12-16]$, which has caused public concerns for their potential environmental and human health impacts. TBBPA is known to show endocrine disruption effects, immunotoxicity, neurotoxicity and reproductive-development toxicity [17]. The TBBPA derivatives, such as TBBPA-BAE, TBBPA-BDBPE, TBBPA-BGE and TBBPA-BHEE have been found to cause neurotoxicity to rat pheochromocytoma cells, with TBBPA-BHEE exhibiting the highest toxicity [18]. Besides, some researches have reported the potential immunotoxicity of TBBPA-BAE [19], neurotoxicity of TBBPA-BAE [20] and maternal transfer properties of TBBPA-BDBPE [21]. Besides, the decomposition products of the TBBPA/S and their derivatives during the pyrolysis, combustion and degradation process may also lead to environmental and health risks [22,23]. Therefore, to evaluate the environmental effect and potential health impact of these BFRs, it was imperative to develop sensitive analytical methods for the determination of TBBPA/S and their derivatives.

The recent analytical methods for TBBPA/S and their derivatives were mainly based on mass spectrometry (MS) techniques, including gas chromatography-mass spectrometry (GC-MS) and liquid chromatography-mass spectrometry (LC-MS) [24]. However, the GC-MS method was not suitable for the analysis of the TBBPA/s and their derivatives because of the thermal degradation in the process of programming temperature increase and farfetched mass spectrum explanation of the target compounds [10]. High-performance liquid chromatography (HPLC) hyphenated with MS has been used to analyze some certain TBBPA derivatives by employing different ionization sources, such as electrospray ionization (ESI) [9], atmospheric pressure photoionization (APPI) [10] and atmospheric pressure chemical ionization (APCI) [20]. However, ESI has poor sensitivity for detection of TBBPA and TBBPS derivatives because of their weak polarity [25]. For example, the ESI source could not produce any precursor ions for TBBPA-BAE and TBBPA-BDBPE under full-scan optimization [15]. The APCI could obtain the specific spectrum of TBBPA BDBPE, but the sensitivity was not enough for the trace level determination of these derivatives [15]. APPI-MS has been applied for specific detection of TBBPA-BAE, TBBPA-BDBPE and TBBPS-BDBPE [10], but the need of an appropriate dopant agent for ionization and the unpopularity of the APPI source significantly limited its wide applications [26]. Currently, the determination of TBBPA-BAE and TBBPA-BDBPE was mainly based on the HPLC coupled with diode array detector (DAD) or ultra violet (UV) detector [27-29], but the low sensitivity usually required preconcentration and the low specificity and selectivity also limited its application in real environmental sample analysis. Hence, up to now there are still lack of reliable and sensitive methods to determine these derivatives, especially TBBPA-BAE and TBBPA-BDBPE.

Recently, inductively coupled plasma mass spectrometry (ICPMS) has been reported as a sensitive and selective detector for the determination of polybrominated diphenyl ethers (PBDEs) by monitoring the signal of bromine [30-32]. However, the research on the determination of the other organic compounds by ICP-MS was very limited and to the best of our knowledge, the application of ICP-MS to TBBPA/S or its derivatives analysis has not yet been reported. In this work, we attempted to establish a new and sensitive method for the determination of TBBPA/S and their derivatives by coupling HPLC separation with ICP-MS detection technique. The experimental conditions were optimized for the
Table 1

The HPLC-ICP-MS conditions for TBBPA/S and their derivatives detection.

\begin{tabular}{|c|c|}
\hline \multicolumn{2}{|l|}{ HPLC conditions } \\
\hline Column & $\begin{array}{l}\text { ZORBAX Eclipse Plus C18 column, } \\
150 \times 4.6 \mathrm{~mm}, 5 \mu \mathrm{m}\end{array}$ \\
\hline Mobile phase & $\begin{array}{l}\text { A: methanol }(0.1 \% \text { (v/v) acetic acid); B: } \\
\mathrm{H}_{2} \mathrm{O}(0.1 \% \text { (v/v) acetic acid) } \\
0 \sim 3 \mathrm{~min} \text {, from } 80 \text { to } 90 \% \text { A, from } 20 \% \\
\text { to } 10 \% \text { B } \\
3 \sim 12 \mathrm{~min} \text {, from } 90 \text { to } 100 \% \text { A, from } \\
10 \% \text { to } 0 \% \text { B } \\
12 \sim 15 \mathrm{~min}, 100 \% \text { A, } 0 \% \text { B } \\
15 \sim 16 \mathrm{~min} \text {, from } 100 \text { to } 80 \% \text { A, from } \\
0 \% \text { to } 20 \% \text { B } \\
16 \sim 20 \mathrm{~min}, 80 \% \text { A, } 20 \% \text { B } \\
20 \text { min, stop }\end{array}$ \\
\hline Flow rate of mobile phase & $1.0 \mathrm{~mL} \mathrm{~min}^{-1}$ \\
\hline Injection volume & $50 \mu \mathrm{L}$ \\
\hline \multicolumn{2}{|l|}{ ICP-MS conditions } \\
\hline RF Power & $1600 \mathrm{~W}$ \\
\hline Smpl Depth & $8.0 \mathrm{~mm}$ \\
\hline Carrier Gas & $0.4 \mathrm{~L} / \mathrm{min}$ \\
\hline Makeup Gas & $0 \mathrm{~L} / \mathrm{min}$ \\
\hline Optional Gas & $\begin{array}{l}30 \% \text { optional gas, containing } 20 \% \mathrm{O}_{2} \text { in } \\
\mathrm{Ar}\end{array}$ \\
\hline Reaction gas & $\mathrm{H}_{2}, 4.5 \mathrm{~mL} / \mathrm{min}$ \\
\hline peristaltic pump & $0.3 \mathrm{rps}$ \\
\hline Temperature of spray chamber & $-5^{\circ} \mathrm{C}$ \\
\hline Monitored isotope $(\mathrm{m} / \mathrm{z})$ & $\mathrm{Q} 1,79\left(\mathrm{Br}^{+}\right) \rightarrow \mathrm{Q} 279\left(\mathrm{Br}^{+}\right)$ \\
\hline Integration time & $0.5 \mathrm{~s}$ \\
\hline
\end{tabular}

simultaneous separation and quantification of TBBPA/S and their derivatives, including TBBPA, TBBPA-BHEE, TBBPA-BGE, TBBPABAE, TBBPA-BDBPE, TBBPS, and TBBPS-BDBPE, by monitoring bromine signals. The established method was then utilized to detect TBBPA/S and the derivatives in environmental water samples.

\section{Experimental}

\subsection{Chemicals and materials}

TBBPA (97\%), TBBPA-BAE (99\%), TBBPA-BGE (purity unknown), TBBPA-BHEE (98\%) and TBBPA-BDBPE (99\%) were purchased from the Sigma-Aldrich. TBBPS (98\%) and TBBPS-BDBPE (99\%) were obtained from Beijing APIS Biotechnology Ltd. (Beijing, China). The structures of the TBBPA/S and their derivatives were listed on Table S1. All standards were dissolved in methanol and stored at $4{ }^{\circ} \mathrm{C}$. A series of the mixed standard solutions of the seven TBBPA/S and their derivatives $\left(5,10,50,100,200 \mu \mathrm{g} \mathrm{L}^{-1}\right)$ and the spiking solutions were prepared by serial dilution of appropriate stock solutions with methanol-water (8:2, v/v). Methanol (Fisher Scientific, Pittsburgh, USA) and dichloromethane (DCM, J.T. Baker, USA) were all HPLC grade. The hydrochloric acid (Fisher scientific, Canada) was trace metal grade. All other chemicals were at least of analytical grade or better. De-ionized water $(18.2 \mathrm{M} \Omega \mathrm{cm})$ was generated by a Milli-Q Advantage A10 system (Millipore, Bedford, USA) and used throughout the experiment.

\subsection{Instrumentation}

The experiments were carried out by using a high performance liquid chromatography (HPLC, Agilent 1200 HPLC Pump, Agilent Technologies Inc., Germany) coupled with inductively coupled plasma tandem mass spectrometry (ICP-MS/MS, Agilent 8800 , Agilent Technologies Inc., Tokyo, Japan). The operating conditions of HPLC-ICP-MS system were summarized in Table 1. The separation of the TBBPA/S and derivatives were performed by a ZORBAX Eclipse Plus C18 column $(4.6 \times 150 \mathrm{~mm}, 5 \mu \mathrm{m}$, Agilent) with methanol and water as the mobile phases. A gradient 
elution using two phases, i.e. A (methanol with addition of $0.1 \%(\mathrm{v} / \mathrm{v})$ acetic acid) and $B$ (water with addition of $0.1 \%(v / v)$ acetic acid) was applied at a flow rate of $1 \mathrm{~mL} / \mathrm{min}$. The details of the step-gradient program was showed in Table 1.

The ICP-MS instrument was tuned and optimized for the quantification of $\mathrm{Br}(\mathrm{m} / \mathrm{z} 79)$ at the beginning of the experiment every day. A standard Scott-type spray chamber was used in the introduction system of ICP-MS and the temperature was set as $-5^{\circ} \mathrm{C}$. A torch with a $1.0 \mathrm{~mm}$ ID injector tube for the analysis of organic compounds was used, with a plasma gas flow rate of $15 \mathrm{~L} \mathrm{~min}^{-1}$ and carrier gas flow rate of $0.4 \mathrm{~L} \mathrm{~min}^{-1}$. The reaction gas in the collision/reaction cell was optimized for the determination of $\mathrm{Br}$ to eliminate the spectral interferences and hydrogen $\left(\mathrm{H}_{2}\right)$ was finally selected as the reaction gas. The optional gas of $\mathrm{O}_{2}$ (containing $20 \%$ $\mathrm{O}_{2}$ in $\mathrm{Ar}$ ) was used and optimized to maintain a robust plasma. The $\mathrm{RF}$ power was set at $1600 \mathrm{~W}$ and the integration time for $\mathrm{Br}$ at $\mathrm{m} / \mathrm{z}$ 79 was $0.5 \mathrm{~s}$ in the experiment.

\subsection{Samples and pretreatment}

Tap water sample was collected directly from the lab. The river water sample was collected from Pan River (Taian, Shandong province). The sea water sample was collected from Shandong province (China). The sea water and river water samples were stored at $4{ }^{\circ} \mathrm{C}$ before detection. The water samples were then extracted by liquid-liquid extraction after filtration through $0.45 \mu \mathrm{m}$ membranes as described previously [33]. In detail, the $\mathrm{pH}$ of the river samples were adjusted to $4-5$ with $1 \mathrm{M} \mathrm{HCl}$. Then $200 \mathrm{~mL}$ of water samples were extracted three times with $100 \mathrm{~mL}$ DCM. The organic extracts were combined, concentrated to approximately $1 \mathrm{~mL}$ by rotary evaporator, blown dried with nitrogen flow and finally, transferred into $1 \mathrm{~mL}$ methanol-water $(8: 2, \mathrm{v} / \mathrm{v})$ prior to the analysis by the proposed HPLC-ICP-MS. The spiking experiment was performed by adding different concentrations $\left(0.005 \mu \mathrm{g} \mathrm{L}^{-1}\right.$, $0.05 \mu \mathrm{g} \mathrm{L}^{-1}$ and $0.5 \mu \mathrm{g} \mathrm{L}^{-1}$ ) of the seven standard compounds into the water samples prior to the extraction procedure. Then the spiking water samples were extracted by the above liquid-liquid extraction method before analysis. All the extraction and analysis were performed in three parallel water samples and four parallel spiked water samples.

\section{Results and discussion}

\subsection{Optimization of ICP-MS parameters for the determination of $\mathrm{Br}$}

The TBBPA and its derivatives was quantified by the determination of ${ }^{79} \mathrm{Br}$ or ${ }^{81} \mathrm{Br}$ in the compounds by ICP-MS. The determination of $\mathrm{Br}$ by the conventional mode of ICP-MS is seriously hampered by the spectral interference of ${ }^{38} \mathrm{Ar}^{40} \mathrm{Ar}^{1} \mathrm{H}$ and ${ }^{40} \mathrm{Ar}^{40} \mathrm{Ar}^{1} \mathrm{H}$ on both of the bromine isotopes of ${ }^{79} \mathrm{Br}$ (50.69\%) and ${ }^{81} \mathrm{Br}$ (49.31\%), respectively. To eliminate the spectral interferences and obtain higher sensitivities, both the no gas mode and collision/reaction cell mode of ICP-MS were evaluated. A set of Br standard solutions (1-100 ng g $^{-1}$ ) was determined by ICP-MS with no gas mode and collision/reaction cell mode with helium $(\mathrm{He})$ and hydrogen $\left(\mathrm{H}_{2}\right)$ as reaction gases, respectively (Fig. S1). The results showed that the use of reaction gases significantly eliminated the interferences and decreased the baseline values of ${ }^{79} \mathrm{Br}$ and ${ }^{81} \mathrm{Br}$ in comparison with the no gas mode. For instance, the background equivalent concentration (BEC) for bromine was $3.7 \mu \mathrm{g} \mathrm{L}^{-1}$ under the no gas mode, while it decreased to $0.3-0.4 \mu \mathrm{g} \mathrm{L}^{-1}$ with the use of reaction gases. Besides, it was observed that the signal intensity of both ${ }^{79} \mathrm{Br}$ and ${ }^{81} \mathrm{Br}$ by using $\mathrm{H}_{2}$ as the reaction gas (Fig. S1C) was five times higher than that by using $\mathrm{He}$ as the reaction gas (Fig. S1b) in the reaction

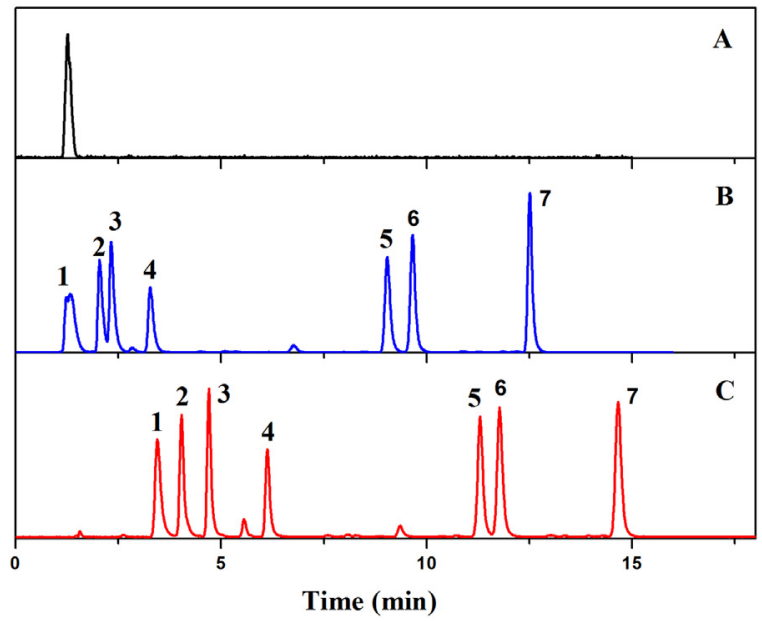

Fig. 1. HPLC-ICP-MS chromatography of inorganic bromide (A) and TBBPA/S and their derivatives without $(B)$ and with $(C)$ acetic acid added in the mobile phase. Peaks: 1, TBBPS; 2, TBBPA-BHEE; 3, TBBPA; 4, TBBA-BGE; 5, TBBPA-BAE; 6, TBBPSBDBPE; and 7, TBBPA-BDBPE.

cell. The instrumental limits of detection (LODs) of ${ }^{79} \mathrm{Br}$ and ${ }^{81} \mathrm{Br}$ by using $\mathrm{H}_{2}$ was $0.1 \mu \mathrm{gL}^{-1}$, but the LODs by using $\mathrm{He}$ as the reaction gas was 0.3 and $0.7 \mu \mathrm{g} \mathrm{L}^{-1}$, respectively. Therefore, considering both the interferences and the sensitivity, the collision/reaction cell mode with $\mathrm{H}_{2}$ as the reaction gas was selected as the most appropriate approach for the detection of $\mathrm{Br}$ by ICP-MS. Besides, the introduction of organic solvent in the mobile phase of HPLC into ICP would result in instability or even extinguish of the plasma and carbon deposits on the torch and the cones during the quantification of the TBBPAs. Therefore, to maintain a stable plasma and detect the bromine-containing compounds in the organic solvent system, the optional gas of oxygen $\left(\mathrm{O}_{2}\right.$, containing $\mathrm{O}_{2} 20 \%$ in $\left.\mathrm{Ar}\right)$ was used and the optional gas ration was optimized to be $30 \%$.

\subsection{Optimization of the HPLC conditions}

For the separation of the TBBPA/S and their derivatives, the reverse phase $\mathrm{C} 18$ column was selected and methanol/water was used as the mobile phase. To obtain better separation conditions and improve the analytical efficiency, different gradient elutions of the mobile phase were optimized. It was found that the peaks of TBBPA-BHEE and TBBPS would be overlapped if the initial concentration of methanol was higher than $80 \%$. After optimization, the concentration of methanol in the mobile phase and the gradient elution procedure was listed in Table 1. This gradient elution was successfully carried out for the baseline separation of seven TBBPA/S and derivatives within $16 \mathrm{~min}$. However, the retention of TBBPS on the column was very weak and the peak was overlapped with that of the inorganic forms of bromide (Fig. 1A and B). For the separation of inorganic $\mathrm{Br}$ forms from the organic compounds, $0.1 \%$ $(\mathrm{V} / \mathrm{V})$ of acetic acid was added into the mobile phase. The addition of acetic acid in the mobile phase did not affect the retention time of $\mathrm{Br}^{-}$and $\mathrm{BrO}_{3}{ }^{-}$because they did not retain on the column, but it prolonged the retention times of TBBPS and the other compounds (Fig. 1C). Therefore, the baseline separation of TBBPS and the inorganic bromide was achieved with the addition of acetic acid in the mobile phase. Moreover, the peak splitting and peak tail problems of TBBPS were also improved when the acetic acid was added in the mobile phase. 
Table 2

The analytical performance of the developed HPLC-ICP-MS method for detection of TBBPA/s and their derivatives.

\begin{tabular}{|c|c|c|c|c|c|c|c|}
\hline \multirow[t]{2}{*}{ Analytes } & \multirow{2}{*}{$\begin{array}{l}\text { Linear Range } \\
\left(\mu \mathrm{g} \mathrm{L}^{-1}\right)\end{array}$} & \multirow{2}{*}{$\begin{array}{l}\text { Correlation } \\
\text { coefficient }\end{array}$} & \multirow{2}{*}{$\begin{array}{l}\mathrm{LOD}^{\mathrm{a}} \\
\left(\mu \mathrm{gL}^{-1}\right)\end{array}$} & \multirow{2}{*}{$\begin{array}{l}\mathrm{IDL}^{\mathrm{b}} \\
(\mathrm{pg})\end{array}$} & \multirow{2}{*}{$\begin{array}{l}\text { MDL } \\
\left(\mathrm{ng} \mathrm{L}^{-1}\right)\end{array}$} & \multicolumn{2}{|l|}{ RSD (\%) } \\
\hline & & & & & & Intra-day $^{c}$ & Inter-day \\
\hline TBBPA & $5-200$ & 0.9991 & 0.12 & 6 & 0.71 & 2.0 & 6.5 \\
\hline TВBPA-BHEE & $5-200$ & 0.9993 & 0.14 & 7 & 0.86 & 1.5 & 5.8 \\
\hline TBBPA-BGE & $5-200$ & 0.9995 & 0.19 & 9.5 & 1.16 & 1.8 & 5.9 \\
\hline TВBPA-BAE & $5-200$ & 0.9995 & 0.14 & 7 & 0.88 & 2.2 & 6.8 \\
\hline TBBPA-BDBPE & $5-200$ & 0.9996 & 0.12 & 6 & 0.77 & 1.9 & 7.3 \\
\hline TBBPS & $5-200$ & 0.9994 & 0.17 & 8.5 & 1.13 & 1.7 & 6.5 \\
\hline TBBPS-BDBPE & $5-200$ & 0.9996 & 0.13 & 6.5 & 0.81 & 1.9 & 6.7 \\
\hline
\end{tabular}

a The instrumental limits of detection (LOD) was calculated based on the $3 \mathrm{~S} / \mathrm{N}$.

b Absolute detection limits (pg) based on a $50 \mu \mathrm{L}$ sample injection.

c RSDs of intra-day, $100 \mu \mathrm{g} \mathrm{L}^{-1}, \mathrm{n}=5$.

d RSDs of inter-day, $100 \mu \mathrm{g} \mathrm{L}^{-1}, \mathrm{n}=1$ per day for 5 days.

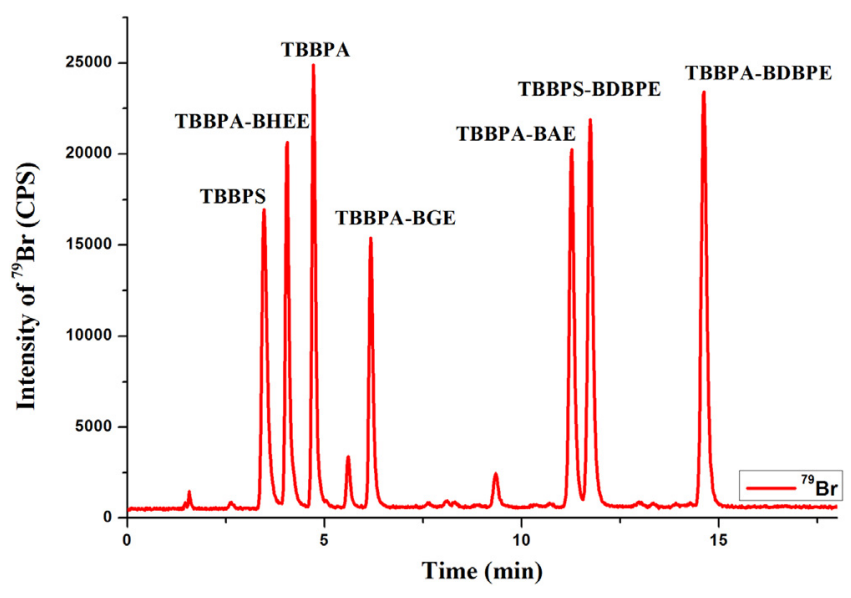

Fig. 2. HPLC-ICP-MS chromatography of mixed standard solutions of TBBPA, TBBPABHEE, TBBA-BGE, TBBPA-BAE, TBBPA-BDBPE, TBBPS, and TBBPS-BDBPE $\left(100 \mu \mathrm{g} \mathrm{L}^{-1}\right)$ under the optimized conditions.

\subsection{Analytical performance}

Under the optimized conditions, seven TBBPA/S and derivatives including TBBPA, TBBPA-BHEE, TBBA-BGE, TBBPA-BAE, TBBPABDBPE, TBBPS, and TBBPS-BDBPE were baseline separated and quantified within 16 min by using the present method (Fig. 2). To validate the developed HPLC-ICP-MS method, the linearity, correlation coefficient, limit of detection and repeatability were tested using a series of standard solutions of the seven BFRs $(5,10,50,100$, $200 \mu \mathrm{g} \mathrm{L}^{-1}$ ). The analytical features are summarized in Table 2. The range of linearity was $5.0-200 \mu \mathrm{g} \mathrm{L}^{-1}$, with the correlation coefficients $\left(r^{2}\right)$ better than 0.999 for all the TBBPA/S and derivatives. The relative standard deviations (RSDs) of the peak area for the seven target compounds ranged from $1.5 \%$ to $2.2 \%$ and $5.8 \%$ to $7.3 \%$ for intra-day $(n=5)$ and inter-day $(n=5)$ measurements, respectively, while the RSDs of the retention time for the seven compounds were less than $0.2 \%$ for intra-day $(n=5)$ and less than $0.9 \%$ for interday $(n=5)$ analysis. These results indicated a good repeatability and precision of the proposed method. The instrument limits of detection (LODs, 3 times the signal-to-noise ratio) for the TBBPA, TBBPA-BHEE, TBBPA-BGE, TBBPA-BAE, TBBPA-BDBPE, TBBPS and TBBPS-BDBPE were determined to be $0.12,0.14,0.19,0.14,0.12$, 0.17 and $0.13 \mu \mathrm{g} \mathrm{L}^{-1}$, respectively and the LODs for $\mathrm{Br}$ was in the range of $0.07-0.10 \mu \mathrm{g} \mathrm{L}^{-1}$. The instrumental detection limits (IDLs) were equal to $6-9.5 \mathrm{pg}$ based on a sample injection volume of $50 \mu \mathrm{L}$. The method detection limits (MDLs, 3 times the signal-to-noise ratio) were based on the replicate analyses $(n=3)$ of blank tap water sample spiked with target compounds at concentration of
$0.5 \mu \mathrm{g} \mathrm{L}^{-1}$. The MDLs of the target compounds ranged from 0.71 to $1.16 \mathrm{ng} \mathrm{L}^{-1}$ for water samples.

In comparison with the recent published articles, the proposed HPLC-ICP-MS method allowed simultaneous separation and sensitive quantification of the TBBPA/S and their five derivatives, especially the TBBPA-BAE and TBBPA-BDBPE. The sensitivity of the ICP-MS was in the range of $1.5 \times 10^{2} \sim 2.3 \times 10^{2}$ CPS per $\mu \mathrm{g} / \mathrm{L}$ for the detection of the seven BFRs. The LODs of the presented method for TBBPA-BAE $\left(0.14 \mu \mathrm{g} \mathrm{L}^{-1}\right)$ were better than the APPI-MS/MS ( $0.24 \mu \mathrm{g} \mathrm{L}^{-1}$ by our conversion) [10] and one to two orders of magnitude lower than the ESI-MS/MS (LOD $=1.96 \mu \mathrm{g} \mathrm{L}^{-1}$ ) [9], the APCI-MS method $\left(2 \mu \mathrm{gL}^{-1}\right)$ [20] and the HPLC-DAD ( $\mathrm{LOD}=10 \mu \mathrm{g} \mathrm{L}^{-1}$ ) method [14] (LOD values was converted into same unit). The LOD of this method for TBBPA-BDBPE $\left(0.12 \mu \mathrm{g} \mathrm{L}^{-1}\right)$ was better than the LC-APPI-MS/MS method $\left(0.64 \mu \mathrm{g} \mathrm{L}^{-1}\right.$ by our conversion) [10] and two or three orders of magnitude lower than the HPLC-DAD method by Robert et al. (10-22 $\left.\mu \mathrm{g} \mathrm{L}^{-1}\right)$ and [27] and Liu et al. ( $100 \mu \mathrm{g} \mathrm{L}^{-1}$ by our conversion) [14]. Besides, the ESI-MS/MS method reported by Tian et al. [9] would introduce large concentrations of $\mathrm{AgNO}_{3}$ to the instrument and may cause instrument damnification [24]. The LODs of other target compounds was close to or better than the previously reported techniques. For instance, the sensitivity of this method for the TBBPA derivatives was even better than that of the solid-phase microextraction (SPME) - HPLC method (0.13-0.63 $\mu \mathrm{g} \mathrm{L}^{-1}$ ) after enrichment of 121-490 times for the TBBPA derivatives [28].

\subsection{Real sample analysis}

In order to verify the application of the established method, seven BFRs in the environmental water samples, including river water, sea water, and tap water were analyzed by the proposed HPLC-ICP-MS method and quantified with external standard method. A series of standard solutions $\left(5,10,50,100,200 \mu \mathrm{g} \mathrm{L}^{-1}\right)$ were determined to make the calibration curve for the TBBPA/S and the derivatives. The typical chromatography of the samples and spiking tap water samples were shown in Fig. 3 and the analytical results were summarized in Table 3 . In the river water sample, only TBBPA-BHEE $\left(10.1 \pm 0.73 \mathrm{ng} \mathrm{L}^{-1}\right)$ was detected. In the sea water samples, TBBPA and TBBPA-BHEE was found to be $8.41 \pm 3.15 \mathrm{ng} \mathrm{L}^{-1}$ and $11.0 \pm 3.10 \mathrm{ng} \mathrm{L}^{-1}$, respectively. TBBPABHEE $\left(3.78 \pm 0.27 \mathrm{ng} \mathrm{L}^{-1}\right)$ was detected in the tap water sample. The concentrations of the other TBBPA/S and derivatives in the water samples were all below the LODs of the present method. Two different concentrations $\left(0.05 \mu \mathrm{g} \mathrm{L}^{-1}\right.$ and $\left.0.5 \mu \mathrm{g} \mathrm{L}^{-1}\right)$ of the seven TBBPA/S and derivatives were added into the river water and sea water samples for spiking recovery experiments and satisfactory spiking recoveries were achieved. The recoveries for the river water and sea water samples were in the range of $95.4 \%-103 \%$ and 


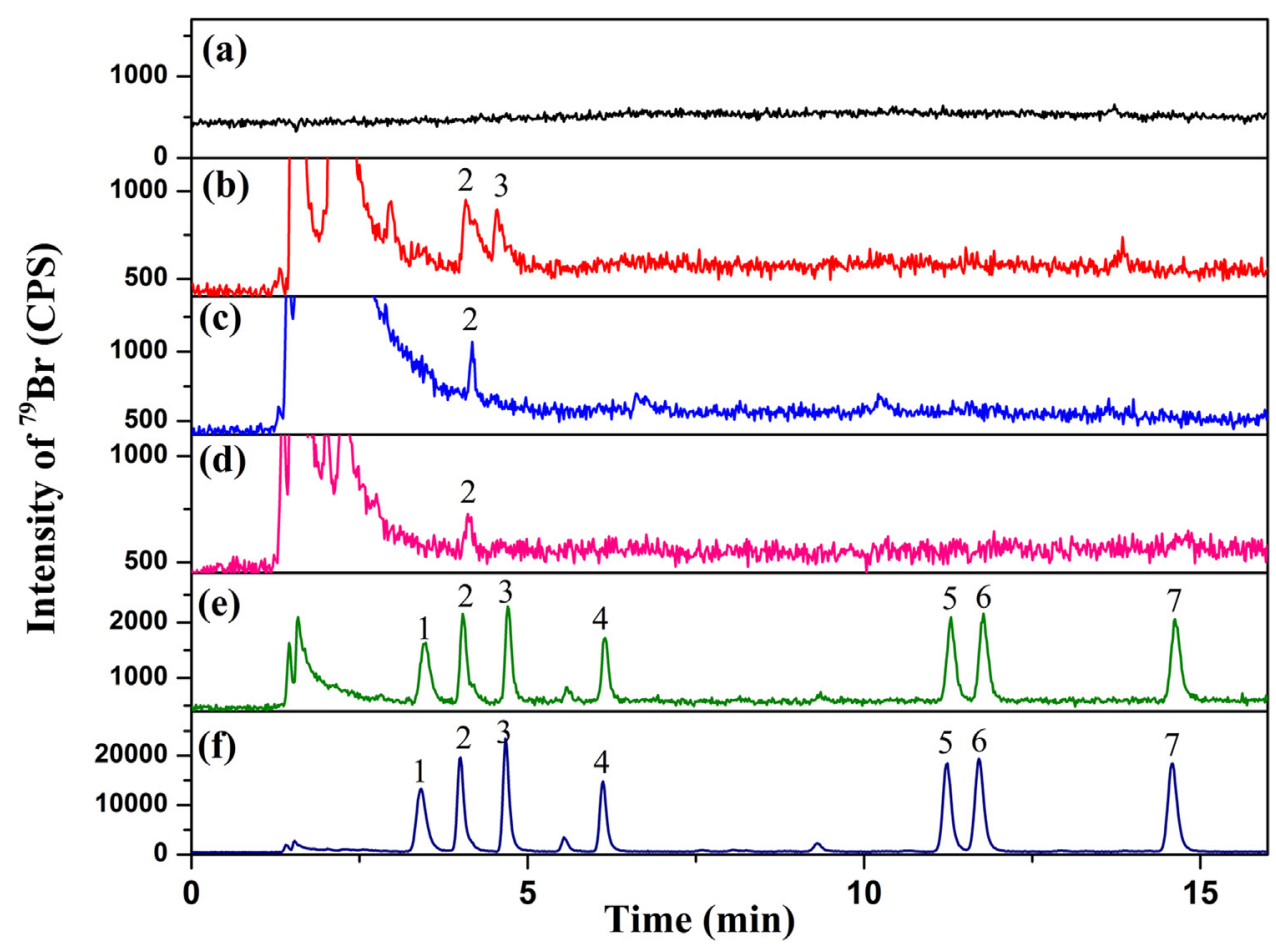

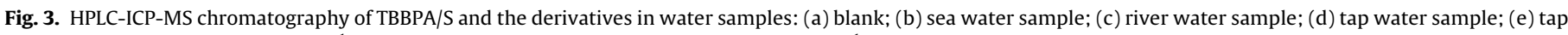

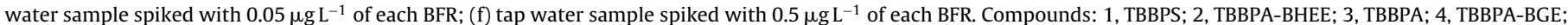
5, TBBPA-BAE; 6, TBBPS-BDBPE; 7, TBBPA-BDBPE.

Table 3

Concentrations and spiking recoveries of the TBBPA/S and their derivatives in water samples quantified by HPLC-ICP-MS.

\begin{tabular}{|c|c|c|c|c|c|c|c|}
\hline Water sample & ТВВРА & TВBPA-BHEE & TBBPA-BGE & TBBPA-BAE & TBBPA-BDBPE & TBBPS & TBBPS-BDBPE \\
\hline \multicolumn{8}{|l|}{ River Water } \\
\hline Found (ng L ${ }^{-1}$ ) & $\mathrm{nd}^{\mathrm{a}}$ & $10.1 \pm 0.73^{b}$ & nd & nd & nd & nd & nd \\
\hline Recovery $^{\mathrm{c}}(\%)$ & 97.8 & 97.9 & 103 & 103 & 97 & 95.4 & 96.7 \\
\hline Recovery $^{\mathrm{d}}(\%)$ & 95.7 & 94.2 & 92.6 & 90.1 & 87.3 & 88.7 & 88 \\
\hline \multicolumn{8}{|l|}{ Sea Water } \\
\hline Found $\left(\mathrm{ng} \mathrm{L}^{-1}\right)$ & $8.41 \pm 3.15$ & $11.0 \pm 3.10$ & nd & nd & nd & nd & nd \\
\hline Recovery $^{\mathrm{c}}(\%)$ & 92.9 & 98.7 & 96.8 & 113 & 105 & 86.2 & 112 \\
\hline Recovery $^{\mathrm{d}}(\%)$ & 105 & 96.3 & 108 & 107 & 103 & 67.7 & 106 \\
\hline \multicolumn{8}{|l|}{ Tap Water } \\
\hline Found (ng L $\left.{ }^{-1}\right)$ & nd & $3.78 \pm 0.27$ & nd & nd & nd & nd & nd \\
\hline Recovery $^{\mathrm{c}}(\%)$ & 84.7 & 106 & 97.3 & 92.5 & 84.1 & 74 & 86.7 \\
\hline Recovery $^{\mathrm{d}}(\%)$ & 95.5 & 100 & 98.2 & 93.7 & 81.5 & 78.9 & 90 \\
\hline Recovery $^{\mathrm{e}}(\%)$ & 86.6 & 111 & 107 & 112 & 102 & 106 & 91.7 \\
\hline
\end{tabular}

a nd: not detected.

b Average \pm standard division $(\mathrm{n}=3)$.

c Mean recovery $(\mathrm{n}=4)$ by spiking $0.05 \mu \mathrm{g} \mathrm{L}^{-1}$ target compounds in water samples.

d Mean recovery $(n=4)$ by spiking $0.5 \mu \mathrm{g} \mathrm{L}^{-1}$ target compounds in water samples.

e Mean recovery $(n=4)$ by spiking $0.005 \mu \mathrm{g} \mathrm{L}^{-1}$ target compounds in water samples.

$86.2 \%-113 \%$ at the spiking concentration of $0.05 \mu \mathrm{g} \mathrm{L}^{-1}$, while the recoveries were in the range of $87.3 \%-95.7 \%$ and $67.7 \%-108 \%$ at the spiking concentration of $0.5 \mu \mathrm{gL}^{-1}$, respectively. In the tap water sample, three different concentrations $\left(0.005 \mu \mathrm{g} \mathrm{L}^{-1}, 0.05 \mu \mathrm{g} \mathrm{L}^{-1}\right.$ and $0.5 \mu \mathrm{g} \mathrm{L}^{-1}$ ) of the seven target compounds were spiked and the spiking recoveries were also satisfactory, which ranged from $74.0 \%$ - $106 \%, 78.9 \%-100 \%$ and $86.6-112 \%$, respectively. These results showed that the proposed HPLC-ICP-MS was a sensitive and reliable method for the detection of TBBPA/S derivatives.

\section{Conclusion}

In this work, a novel method for the determination of TBBPA/S and their derivatives has been developed based on the HPLC and
ICP-MS/MS hyphenated techniques. The method enables fast, sensitive and simultaneous separation and quantification of TBBPA/S and their derivatives, including TBBPA-BHEE, TBBPA-BGE, TBBPABAE, TBBPA-BDBPE and TBBPS-BDBPE. In comparison with the traditional quantification methods, such as MS/MS or DAD detector, the ICP-MS has obvious advantages in sensitivity for the quantification of TBBPA/S and their derivatives, especially TBBPA-BAE and TBBPA-BDBPE. Under the optimized conditions, this method was successfully applied to analyze the TBBPA/S and their derivatives in river water, sea water and tap water samples with satisfactory recoveries. The proposed method provided an alternative and sensitive tool for the analysis of TBBPA/S and derivatives in water samples and may be applied to more complex samples such as environmental and biological samples in the future. Moreover, this 
study also overcame the problems of the organic reagent intolerance of ICP-MS plasma and the interferences of bromine analysis by the traditional ICP-MS, which provided significant new insight into the determination of novel bromine containing organic compounds by ICP-MS.

\section{Acknowledgements}

This work was supported by the National Nature Science Foundation of P.R. China (Nos. 21605155, 21477156 and 21377155) and the Strategic Priority Research Program of the Chinese Academy of Sciences (XDB14010400).

\section{Appendix A. Supplementary data}

Supplementary data associated with this article can be found, in the online version, at http://dx.doi.org/10.1016/j.chroma.2017.03. 040.

\section{References}

[1] A. Covaci, S. Harrad, M.A.E. Abdallah, N. Ali, R.J. Law, D. Herzke, C.A. de Wit, Novel brominated flame retardants: a review of their analysis, environmental fate and behaviour, Environ. Int. 37 (2011) 532-556

[2] S. Kemmlein, D. Herzke, R.J. Law, Brominated flame retardants in the European chemicals policy of REACH-regulation and determination in materials, J. Chromatogr. A 1216 (2009) 320-333.

[3] R.J. Law, C.R. Allchin, J. de Boer, A. Covaci, D. Herzke, P. Lepom, S. Morris, J. Tronczynski, C.A. de Wit, Levels and trends of brominated flame retardants in the European environment, Chemosphere 64 (2006) 187-208.

[4] EBFRIP questions Norwegian proposal to restrict the use of TBBP-A and HBCD in consumer products, European Brominated Flame Retardant Industry Panel (EBFRIP), statement June 4, 2007.

[5] M.S.E. Mäkinen, M.R.A. Mäkinen, J.T.B. Koistinen, A.-L. Pasanen, P.O. Pasanen, P.J. Kalliokoski, A.M. Korpi, Respiratory and dermal exposure to organophosphorus flame retardants and tetrabromobisphenol a at five work environments, Environ. Sci. Technol. 43 (2009) 941-947.

[6] I. Watanabe, S.-i. Sakai, Environmental release and behavior of brominated flame retardants, Environ. Int. 29 (2003) 665-682.

[7] Environmental Health Criteria 172, Tetrabromobisphenol A and Derivatives, International Programme on Chemical Safety, World Health Organization, Geneva, 1995.

[8] A. Covaci, S. Voorspoels, M.A.-E. Abdallah, T. Geens, S. Harrad, R.J. Law, Analytical and environmental aspects of the flame retardant tetrabromobisphenol-A and its derivatives, J. Chromatogr. A 1216 (2009) 346-363.

[9] Y. Tian, A.-f. Liu, G.-b. Qu, C.-x. Liu, J. Chen, E. Handberg, J.-b. Shi, H.-w. Chen, G.-b. Jiang, Silver ion post-column derivatization electrospray ionization mass spectrometry for determination of tetrabromobisphenol A derivatives in water samples, RSC Adv. 5 (2015) 17474-17481.

[10] R.J. Letcher, S. Chu, High-sensitivity method for determination of tetrabromobisphenol-S and tetrabromobisphenol-A derivative flame retardants in great lakes herring gull eggs by liquid chromatography-atmospheric pressure photoionization-tandem mass spectrometry, Environ. Sci. Technol. 44 (2010) 8615-8621.

[11] European Union Risk Assessment Report. EU RAR CAS No. 79-94-7 EINECS: 201-236-9 2,2',6,6' -tetrabromo-4,4' -isopropylidenedi-phenol (tetrabromobisphenol A or TBBPA) Part II Human Health; European Commission Joint Research Centre: EUR 22161 EN 4th Priority List, Vol. 63. 2006.

[12] N. Ali, S. Harrad, E. Goosey, H. Neels, A. Covaci, Novel brominated flame retardants in Belgian and UK indoor dust: implications for human exposure, Chemosphere 83 (2011) 1360-1365.

[13] P.H. Howard, D.C.G. Muir, Identifying new persistent and bioaccumulative organics among chemicals in commerce, Environ. Sci. Technol. 44 (2010) 2277-2285.
[14] A.-f. Liu, G.-b. Qu, M. Yu, Y.-w. Liu, J.-b. Shi, G.-b. Jiang, Tetrabromobisphenol-A/S and nine novel analogs in biological samples from the chinese bohai sea: implications for trophic transfer, Environ. Sci. Technol. 50 (2016) 4203-4211.

[15] G. Qu, A. Liu, T. Wang, C. Zhang, J. Fu, M. Yu, J. Sun, N. Zhu, Z. Li, G. Wei, Y. Du, J. Shi, S. Liu, G. Jiang, Identification of tetrabromobisphenol a allyl ether and tetrabromobisphenol a 2,3-dibromopropyl ether in the ambient environment near a manufacturing site and in mollusks at a coastal region, environ, Sci. Technol. 47 (2013) 4760-4767.

[16] J.R. Nyholm, R. Grabic, H.P.H. Arp, T. Moskeland, P.L. Andersson, Environmental occurrence of emerging and legacy brominated flame retardants near suspected sources in Norway, Sci. Total Environ. 443 (2013) 307-314.

[17] K. Liu, J. Li, S. Yan, W. Zhang, Y. Li, D. Han, A review of status of tetrabromobisphenol A (TBBPA) in China, Chemosphere 148 (2016) 8-20.

[18] Q. Liu, X. Ren, Y. Long, L. Hu, G. Qu, Q. Zhou, G. Jiang, The potential neurotoxicity of emerging tetrabromobisphenol A derivatives based on rat pheochromocytoma cells, Chemosphere 154 (2016) 194-203.

[19] S. Pullen, R. Boecker, G. Tiegs, The flame retardants tetrabromobisphenol A and tetrabromobisphenol A-bisallylether suppress the induction of interleukin-2 receptor $\alpha$ chain (CD25) in murine splenocytes, Toxicology 184 (2003) 11-22.

[20] G. Qu, J. Shi, T. Wang, J. Fu, Z. Li, P. Wang, T. Ruan, G. Jiang, Identification of tetrabromobisphenol a diallyl ether as an emerging neurotoxicant in environmental samples by bioassay-directed fractionation and HPLC-APCI-MS/MS, Environ. Sci. Technol. 45 (2011) 5009-5016.

[21] J.R. Nyholm, A. Norman, L. Norrgren, P. Haglund, P.L. Andersson, Maternal transfer of brominated flame retardants in zebrafish (Danio rerio), Chemosphere 73 (2008) 203-208.

[22] N. Ortuño, J. Moltó, J.A. Conesa, R. Font, Formation of brominated pollutants during the pyrolysis and combustion of tetrabromobisphenol A at different temperatures, Environ. Pollut. 191 (2014) 31-37.

[23] M. Altarawneh, B.Z. Dlugogorski, Mechanism of thermal decomposition of tetrabromobisphenol A (TBBA), J. Phys. Chem. A 118 (2014) 9338-9346.

[24] G. Qu, A. Liu, L. Hu, S. Liu, J. Shi, G. Jiang, Recent advances in the analysis of TBBPA/TBBPS, TBBPA/TBBPS derivatives and their transformation products, TrAC Trends Anal. Chem. 83 (Part B) (2016) 14-24.

[25] A.F. Liu, Y. Tian, N.Y. Yin, M. Yu, G.B. Qu, J.B. Shi, Y.G. Du, G.B. Jiang, Characterization of three tetrabromobisphenol-S derivatives in mollusks from chinese bohai sea: a strategy for novel brominated contaminants identification, Sci. Rep. 5 (2015).

[26] Y. Tian, J. Chen, Y.-z. Ouyang, G.-b. Qu, A.-f. Liu, X.-m. Wang, C.-x. Liu, J.-b. Shi, H.-w. Chen, G.-b. Jiang, Reactive extractive electrospray ionization tandem mass spectrometry for sensitive detection of tetrabromobisphenol A derivatives, Anal. Chim. Acta 814 (2014) 49-54.

[27] R. Köppen, R. Becker, C. Jung, C. Piechotta, I. Nehls, Investigation of extraction procedures and HPLC-DAD/MS for the determination of the brominated flame retardant tetrabromobisphenol A bis(2,3-dibromopropylether) in environmental samples, Anal. Bioanal. Chem. 384 (2006) 1485-1492.

[28] X. Wang, J. Liu, Q. Liu, X. Du, G. Jiang, Rapid determination of tetrabromobisphenol A and its main derivatives in aqueous samples by ultrasound-dispersive liquid-liquid microextraction combined with high-performance liquid chromatography, Talanta 116 (2013) 906-911.

[29] X. Wang, J. Liu, A. Liu, Q. Liu, X. Du, G. Jiang, Preparation and evaluation of mesoporous cellular foams coating of solid-phase microextraction fibers by determination of tetrabromobisphenol A, tetrabromobisphenol $\mathrm{S}$ and related compounds, Anal. Chim. Acta 753 (2012) 1-7.

[30] K. Bierla, A. Riu, L. Debrauwer, D. Zalko, B. Bouyssiere, J. Szpunar, Screening for polybrominated diphenyl ethers in biological samples by reversed-phase fast HPLC-ICP MS, J. Anal. At. Spectrom. 25 (2010) 889-892.

[31] S. Mingwu, W. Chao, J. Yongjuan, D. Xinhua, F. Xiang, Determination of selected polybrominated diphenylethers and polybrominated biphenyl in polymers by ultrasonic-assisted extraction and high-performance liquid chromatography-inductively coupled plasma mass spectrometry, Anal. Chem. 82 (2010) 5154-5159.

[32] A. Gonzalez-Gago, D. Pröfrock, A. Pange, Comparison of GC-NCI MS, GC-ICP-MS, and GC-EI MS-MS for the determination of PBDEs in water samples according to the water framework directive, Anal. Bioanal. Chem. 407 (2015) 8009-8018.

[33] A. Liu, G. Qu, C. Zhang, Y. Gao, J. Shi, Y. Du, G. Jiang, Identification of two novel brominated contaminants in water samples by ultra-high performance liquid chromatography-orbitrap fusion tribrid mass spectrometer, J. Chromatogr. A 1377 (2015) 92-99. 